\title{
Study of Risk Evaluation for Complex Projects under BIM and IPD Collaborative Pattern Based on Neighborhood Rough Sets
}

\author{
Weibing CHEN, Junwu WANG, Chengfu WANG
}

\begin{abstract}
Faced with the existing problems in the construction industry, project managers have been aware that traditional project delivery patterns cannot satisfy the current building industry's pursuit of high-quality economic benefits or cope with the increasing volume and complexity of modern buildings. Therefore, whole-process comprehensive management has become a new development trend for engineering projects, the traditional project delivery pattern should be changed, and early-stage communication, cooperation, and information sharing among project participants should be strengthened. As for the BIM and IPD collaborative pattern, the emphasis is laid on collaboration among project members, and the core idea lies in benefit and risk sharing and full consideration of human resources, commercial structure and engineering system of projects. The advent of IPD pattern has well solved problematic issues encountered in engineering projects, where risk problem has attracted the highest attention. Risk factors of IPD projects were reduced and screened out based on attribute reduction theory of rough sets, and primary risk factors influencing smooth implementation of IPD projects were obtained.
\end{abstract}

Keywords: BIM; domain rough set; IPD model; risk evaluation

\section{INTRODUCTION}

With rapid economic development, all kinds of construction projects are presenting trends of scale expansion and technological complication and constructing parties, which are having higher requirements, and these changes have proposed more professional and higher requirements for consultation, design and construction in the whole engineering project construction process, and even for economic benefits of the building industry. Faced with the existing problems in the building industry, more and more experts and project managers have been aware that traditional project delivery patterns cannot satisfy the current building industry's pursuit of high-quality economic benefits or cope with the increasing volume and complexity of modern buildings, so wholeprocess comprehensive management has become a new development trend for engineering projects. A survey by the American Institute of Architects (AIA) in 2017 pointed out that [1], $83 \%$ of proprietors required to change the traditional project delivery patterns and strengthen earlystage communication, cooperation and information sharing among project participants, which realize overall project optimization to the greatest extent. The vigorous popularization of building information modeling (BIM) technology even poses a greater challenge to the traditional delivery patterns, and its implementation has boosted the reform of the building industry and elevated the production efficiency of the building industry and overall project benefits. Integrated project delivery (IPD) pattern was used in the oil drilling platform project in the North Sea in Britain at the end of the 1990s at the earliest, which achieved success in Australian and American projects. IPD pattern lays the emphasis on collaboration among project members, and its core idea lies in risk and benefit sharing and full consideration of commercial structure, human resources, and engineering system of the projects. Based on BIM technology and by reference to related theories of lean construction, projects can reach both local and global optimum. Among general transaction patterns, project participants aim at safeguarding their own benefits but not caring about benefits of counterparties and overall project benefits, thus obstructing communication among project members, increasing workload of design change and site visa of the projects and reducing project efficiency and benefits. The advent of IPD pattern has well solved difficulties encountered in engineering projects.

\section{RESEARCH STATUS OF RISK SHARING OF COMPLEX PROJECTS UNDER BIM-BASED IPD PATTERN}

Risk sharing is an essential path for risk control with the main work being: taking overall consideration of risk control abilities and risk bearing abilities of project participants and reasonably allocating risk factors existing in the projects to the most advantaged participants for risk management and control. Scholars from many countries have investigated risk sharing mainly from qualitative and quantitative angles and focuses on risk preference degree, quantification of influence level of risk factors and benefit distribution. As for qualitative studies of risk sharing, Veg pointed out that the core principle of risk sharing was to realize win-win between participants [2], but there was no fixed normal form for risk sharing, but instead, schemes should be formulated according to concrete situation of the project. As indicated by Frederick, the final goal of project risk sharing was to reduce the total project cost to the minimum [3]. Govan put forward allocating more risk factors to preference parties of risks and parties with strong risk bearing abilities, so as to ensure controllability of overall projects for risk factors [4].

Quantitative research methods of risk sharing mainly include fuzzy mathematical method, statistical analysis method and case study method. Directing at uncertainty and particularity of risks, Elbarkonky proposed a fuzzy emergency discriminant model based on expert investigation method (Delphi method) to evaluate probability of occurrence and influence level of project risks [5]. Nasirzadeh put forward a cooperative negotiation model based on system dynamics to quantitatively analyze risk allocation problems [6]. Karakas developed a multiagent system to simulate risk sharing and cost allocation among all parties [7]. Francesca constructed a game model of final quotation arbitration to estimate different risk sharing proportions of participants [8]. 


\section{RISK IDENTIFICATION METHOD AND PROCESS UNDER BIM-BASED IPD PATTERN}

As the primary link of risk management, risk identification refers to a comprehensive judgment, systematic classification, and scientific appraisal process of types and influence degrees of risk factors possibly existing in projects using IPD pattern. Project risk identification acquires and processes risk information mainly through two aspects: judge through professional knowledge and working experience of related professionals and then acquire information; obtain risk factors by summarizing related data and cases of actual projects. Common project risk identification methods include brain storming method, Delphi method, flowchart method, etc. Delphi method and flowchart method were mainly utilized to perform risk factor identification of the existing IPD projects according to actual requirements.

During the bidding phase of the IPD project, the design unit, construction unit and the owner reached an agreement on the delivery method, that is, an IPD team was formed to identify the main participants of the project. After the owner, design unit and construction unit signed a tripartite contract, the construction unit intervened in the design phase in advance to determine the project risk. The three parties will jointly discuss and determine the main subcontractors of mechanical and electrical, electric power fire protection, and pipelines, and ensure that important subcontractors agree to add people to the project at the design stage, and jointly bear risks and responsibilities, and finally reach management goals and collect risks information. However, some subcontractors with relatively light responsibilities such as laying floors and carpentry still use traditional project management methods, sign total price contracts, and finally determine the estimated project risk situation. The process of forming an IPD team is shown in Fig. 1.

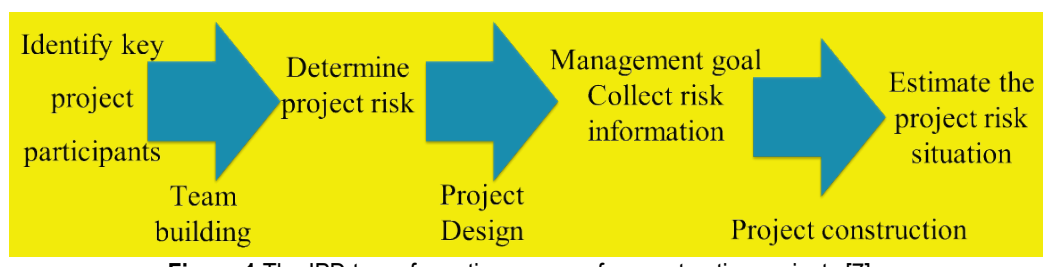

Figure 1 The IPD team formation process for construction projects [7]

The risk identification process of IPD projects is usually divided into four phases: determination of main project participants, confirmation of project risks and management objectives, collection of risk information and estimation of project risk situation. However, the above steps can be combined in the actual implementation process, so the risk identification was carried out according to actual demands in this paper as shown in Tab. 1 and Tab. 2.

Table 1 Determination of risk factors [8]

\begin{tabular}{|c|c|c|}
\hline $\begin{array}{c}\text { Risk } \\
\text { source }\end{array}$ & Risk factor set & Risk factor \\
\hline \multirow{9}{*}{$\begin{array}{l}\text { External } \\
\text { risk }\end{array}$} & \multirow{2}{*}{ Natural risk } & Force majeure \\
\hline & & Geological and climatic condition \\
\hline & \multirow{3}{*}{ Political risk } & Turbulent political scene \\
\hline & & Delay of project review and approval \\
\hline & & Change of laws and regulations \\
\hline & \multirow{3}{*}{ Economic risk } & Inflation \\
\hline & & Tax change \\
\hline & & Change of exchange rate \\
\hline & \multirow{2}{*}{$\begin{array}{c}\text { Early-stage } \\
\text { conceptual phase }\end{array}$} & Project planning \\
\hline \multirow{13}{*}{$\begin{array}{l}\text { Internal } \\
\text { risk }\end{array}$} & & Contract risk \\
\hline & \multirow{4}{*}{ Design phase } & Application of BIM technology \\
\hline & & Design risk \\
\hline & & Communication risk among parties \\
\hline & & Too high early-stage expense \\
\hline & \multirow{8}{*}{$\begin{array}{c}\text { Construction } \\
\text { phase }\end{array}$} & Engineering change \\
\hline & & Construction quality \\
\hline & & Construction schedule \\
\hline & & Construction safety \\
\hline & & Material supply \\
\hline & & Insufficient experience of participant \\
\hline & & Income is lower than the expected \\
\hline & & Change of market demand \\
\hline
\end{tabular}

Table 2 Determination of risk factors [9]

\begin{tabular}{|c|l|}
\hline $\begin{array}{c}\text { Numerical value } \\
\text { attributes }\end{array}$ & \\
\hline a1 & Force majeure \\
\hline a2 & Geological and climatic condition \\
\hline a3 & Turbulent political scene \\
\hline a4 & Delay of project review and approval \\
\hline a5 & Change of laws and regulations \\
\hline a6 & Inflation \\
\hline a7 & Tax change \\
\hline a8 & Change of exchange rate \\
\hline a9 & Project planning \\
\hline a10 & Contract risk \\
\hline a11 & Application of BIM technology \\
\hline a12 & Design risk \\
\hline a13 & Communication risk among parties \\
\hline a14 & Too high early-stage expense \\
\hline a15 & Engineering change \\
\hline a16 & Construction quality \\
\hline a17 & Construction schedule \\
\hline a18 & Construction safety \\
\hline a19 & Material supply \\
\hline a20 & Insufficient experience of participant \\
\hline a21 & Income is lower than the expected \\
\hline a22 & Change of market demand \\
\hline & \\
\hline &
\end{tabular}

\section{SCREENING OF RISK FACTORS OF COMPLEX PROJECTS UNDER BIM-BASED IPD PATTERN}

These risk factors are not only existing risk factors, which are the same as those under the traditional project pattern, but also specific risk factors under IPD pattern. Finding out the primary risk factors influencing smooth completion of IPD projects is the fundamental work of risk management. The corrected Delphi method was utilized in this paper for scoring of risk factors in Tab. 2, and the scoring results are listed in Tab. 3 [9]. Risk factors of IPD projects were reduced and screened out based on the attribute reduction theory of rough sets, and the main risk 
factors influencing smooth implementation of IPD projects were obtained.

\subsection{Basic Concept of Rough Set}

Neighborhood rough set is established on the basis of classical rough sets. The classical rough set was proposed by Professor Z. Pawlak from Warsaw University of Technology in Poland when studying expression and utilization of incomplete data and inaccurate knowledge in 1982 [10]. Belonging to a basic theory in the data mining field, it can objectively mine internal information of data and extract data according to certain principles so as to obtain their connotation information.

Definition 1 [10]: Any subset of (relation) $A \times B$ is a binary relation from set $A$ to set $B$, and it is marked as $R$, namely $R \subseteq A \times B$.

Definition 2: The non-null finite set is constituted by discussion objects we are interested in a domain of discourse and marked as $U$. If domain of discourse $U$ and a cluster of equivalent relation $R$ are given, they will form a tuple [10]. $U$.

$K=(U, R)$ is a knowledge base on domain of discourse

Definition 3 (indistinguishable relation): A knowledge base $K=(U, R)$ is given, if $P \subseteq R$ and $P \neq \varnothing, \cap P$ is still an equivalent relation on domain of discourse $U$, and it is called indistinguishable relation on $P$ and marked as $\operatorname{IND}(P)$, which is simplified as $P[10]$.

Definition 4 (upper approximation and lower approximation of set): If a knowledge base is given, the domain of discourse $U$ can be of multiple divisions (marked as $U / \operatorname{IND}(P))$ and simplified as $(U / P)$ according to indistinguishable relation determined by the subsets [10]

$$
\begin{aligned}
& \underline{R}(X)=\cup\{Y \in U / R: Y \subseteq X\} \\
& \bar{R}(X)=\cup\{Y \in U / R: Y \cap X \neq \varnothing\}
\end{aligned}
$$

$\underline{R}(X)$ is called lower approximation of $X$ and $\bar{R}(X)$ is upper approximation of $X$. The boundary domain of subset $X$ can be obtained as below:

$$
B N_{B}(X)=\bar{R}(X)-\underline{R}(X)
$$

$\operatorname{Pos}_{R}(X)=\underline{R}(X)$ is called $R$ positive domain of subset $X$, and $\operatorname{Neg}_{R}(X)=U-\bar{R}(X)$ is $R$ negative domain of subset $X$.

Definition 5 (rough set and accurate set): A knowledge base $K=(U, R)$ is given, $\forall \mathrm{X} \subseteq \mathrm{U}$. If $\underline{R}(X)=R(\bar{X})$, set $X$ is called an accurate set about domain of discourse - $U$ relative to knowledge (equivalent relation) $R$. If $\underline{R}(X) \neq R(\bar{X})$, set $X$ is a rough set about domain of discourse $U$ relative to knowledge (equivalent relation) $R$ [10].

For a decision system $D S=(U, C \cup D, V, f)$, its internal functions are respectively: $U$ is domain of discourse, $C$ is condition attribute, $D$ is decision attribute, and $C \cap D=\varnothing$, $D \neq \varnothing$, and $V$ is set of attribute values $V_{a}$.

$$
V=\bigcup_{a \in C \cup D} V_{a}
$$

$$
f=U \times(C \cup D) \rightarrow V \text { is an information function, }
$$
which represents mapping relation among samples, attributes and attribute values.

A decision system $D S$ is given, and the dependence degree of $\forall B \subseteq C$ decision attribute $D$ on condition attribute subset $B$ is defined as below:

$\gamma_{B}(D)=\frac{\left|\operatorname{Pos}_{B}(D)\right|}{|U|}$

$|\bullet|$ is base number of the set, namely number of elements in the set. It can be known from formula definition that the dependence degree of decision attribute set on condition attribute subset is namely the proportion of positive domain sets determined by condition attribute subset $B$ in the domain of discourse.

According to Eq. (4) of dependence level and definition of positive domain, a decision system $D S=(U$, $C \cup D, V, f)$, is given, if $B_{1} \subseteq B_{2} \subseteq C$, then $\left|\operatorname{Pos}_{B_{1}}(D)\right| \leq\left|\operatorname{Pos}_{B_{2}}(D)\right| \leq\left|\operatorname{Pos}_{c}(D)\right|$, and the following can be obtained through the formula of dependence degree. $\left|\gamma_{B_{1}}(D)\right| \leq\left|\gamma_{B_{2}}(D)\right| \leq\left|\gamma_{C}(D)\right|$, namely dependence degree presents monotonic decreasing trend as the attribute sets increase.

Definition 6 (knowledge reduction): A knowledge base $K=(U, R)$ and a cluster of equivalent relation $P \subseteq R$ on it are given, and then for any $G \subseteq P$, if $G$ satisfies the following condition:

$G$ is independent, namely each element in $G$ is indispensable;

$I N D(G)=I N D(P)$, namely division of knowledge base is not influenced. $G$ is called a reduction of $P$, and it is marked as $G=\operatorname{Red}(P)$, where $\operatorname{Red}(P)$ is the set constituted by all reductions of $P$.

Definition 7 (kernel of knowledge): Given a knowledge base $K=(U, R)$ and a cluster of equivalents on it, $P \subseteq R$ for any $Q \in P$, if $Q$ satisfies [10].

$$
I N D(P-\{Q\}) \neq I N D(P)
$$

It is said that $Q$ is necessary in $P$, the set constituted by all necessary knowledge in $P$ is the kernel of $P$, denoted as Core $(P)$.

Definition 8 (relative reduction of decision system): Given a decision system $D S=(U, C \cup D, V, f)$ [10].

$B \subseteq C$, if the condition attribute subset $B$ satisfies the following conditions:

1) $\gamma_{B}(D)=\gamma_{C}(D)$, namely, $\operatorname{Pos}_{B}(D)=\operatorname{Pos} C(D)$, condition attribute subsets $B$ and $C$ have the same ability of classification;

2) $\forall a \in B, \gamma_{B}(D)>\gamma_{B-\{a\}}(D)$, that is, there is no redundancy in the subset $B$ of condition attribute;

The condition attribute subset $B$ is called a relative reduction of condition attribute set $C$.

Definition 9 (metric): In a given $\mathrm{N}$-dimensional real 
number space is $\Omega, \Delta=R^{N} \times R^{N} \rightarrow R$, then $\Delta$ is called a measure (distance) on $R^{N}$, if $\Delta$ meets the following conditions:

$\Delta\left(x_{1}, x_{2}\right) \geq 0$, where and only when $x_{1}=x_{2}$, it is equal, $\forall x_{1}, x_{2} \in R^{N}$;

$\Delta\left(x_{1}, x_{2}\right)=\Delta\left(x_{2}, x_{1}\right), \forall x_{1}, x_{2} \in R^{N}$

$\Delta\left(x_{1}, x_{3}\right) \leq \Delta\left(x_{1}, x_{2}\right)+\Delta\left(x_{2}, x_{3}\right), \forall x_{1}, x_{2}, x_{3} \in R^{N}$;

$(\Omega, \Delta)$ is called a metric space. $\Delta\left(x_{i}, x_{j}\right)$ is a distance function that represents the distance between the element $x_{i}$ and the element $x_{j}$. The common distance function is as follows:

Manhattan distance function:

$\Delta\left(x_{i}, x_{j}\right)=\sum_{k=1}^{N}\left|f\left(x_{i}, a_{k}\right)-f\left(x_{j}, a_{k}\right)\right|$

Euclidean distance function:

$\Delta\left(x_{i}, x_{j}\right)=\left\{\sum_{i=1}^{n}\left[f\left(x_{i}, a_{k}\right)-f\left(x_{j}, a_{k}\right)\right]^{2}\right\}^{\frac{1}{2}}$

$P$ norm distance function:

$\Delta\left(x_{i}, x_{j}\right)=\left[\sum_{k=1}^{N}\left|f\left(x_{i}, a_{k}\right)-f\left(x_{j}, a_{k}\right)\right|^{p}\right]^{\frac{1}{p}}$

Definition 10 ( $\delta$ - neighborhood): The nonempty finite set $U=\left\{x_{1}, x_{2}, \ldots x_{n}\right\}$ on a given real number space $\Omega$.

The neighborhood $\delta$ of $\forall \mathrm{x}_{i}$ is defined as:

$\delta\left(x_{i}\right)=\left\{x \mid x \in U, \Delta\left(x, x_{i}\right) \leq \delta\right\}$ among them, $\delta \geq 0$

Definition 11 (upper approximation and lower approximation of neighborhood): Given the nonempty finite set $U=\left\{x_{1}, x_{2}, \ldots x_{n}\right\}$ on real space $\Omega$ and its neighborhood relation $N$, i.e., binary group $N S=(U, N)$, $\forall X \subseteq U$, then the upper approximation and lower approximation of $X$ in neighborhood approximation space $N S=(U, N)$ are respectively:

$$
\bar{N} X=\left\{x_{i} \mid \delta\left(x_{i}\right) \cap X \neq \varnothing, x_{i} \in U\right\}
$$

$$
\underline{N} X=\left\{x_{i} \mid \delta\left(x_{i}\right) \subseteq X, x_{i} \in U\right\}
$$

It can be concluded that the approximate boundary of $X$ is as follows:

$B N(X)=\bar{N} X-\underline{N} X$

Definition 12: Given a neighborhood decision system $N D S=(U, A \cup D)$, the decision attribute $D$ divides the domain of discourse $U$ into $N$ equivalence classes $\left(X_{1}, \ldots, X_{n}\right) \quad \forall B \subseteq A$ the upper and lower approximations of the decision attribute $D$ on subsets $B$ are as follows:

$$
\begin{aligned}
& \bar{N}_{B} X=\left\{x_{i} \mid \delta\left(x_{i}\right) \cap X \neq \varnothing, x_{i} \in U\right\} \\
& \underline{N}_{B} X=\left\{x_{i} \mid \delta\left(x_{i}\right) \subseteq X, x_{i} \in U\right\}
\end{aligned}
$$

Similarly, the boundary of the decision system can be obtained as:

$$
B N(D)=\bar{N}_{B} D-\underline{N}_{B} D
$$

Positive domain and negative domain of the neighborhood decision system are respectively:

$$
\operatorname{Pos}_{B}(D)=\underline{N}_{B} D, \operatorname{Neg}_{B}(D)=U-\bar{N}_{B} D
$$

Dependence degree of decision attribute $D$ on condition attribute $B$ is:

$k_{D}=\gamma_{B}(D)=\frac{\left|\operatorname{Pos}_{B}(D)\right|}{|U|}$

According to the above formula, dependence degree $k_{D}$ is monoclinic $B_{1} \subseteq B_{2} \subseteq B_{3} \subseteq, \ldots, \subseteq A$, and $\gamma_{B_{1}}(D) \leq \gamma_{B_{2}}(D) \leq, \ldots, \leq \gamma_{A}(D)$.

\begin{tabular}{|c|c|c|c|c|c|c|c|c|c|c|c|c|c|c|c|c|c|c|c|c|c|c|c|}
\hline & $a_{1}$ & $a_{2}$ & $a_{3}$ & $a_{4}$ & $a_{5}$ & $a_{6}$ & $a_{7}$ & $a_{8}$ & $a_{9}$ & $a_{10}$ & $a_{11}$ & $a_{12}$ & $a_{13}$ & $a_{14}$ & $a_{15}$ & $a_{16}$ & $a_{17}$ & $a_{18}$ & $a_{19}$ & $a_{20}$ & $a_{21}$ & $a_{22}$ & $d$ \\
\hline$x_{1}$ & 3,1 & 3,0 & 1,4 & 1,5 & 3,3 & 1,4 & 3,2 & 1,6 & 3,1 & 3,2 & 1,5 & 3,7 & 3,5 & 1,2 & 1,4 & 3,5 & 4,1 & 4,2 & 1,1 & 4,3 & 4,3 & 2,3 & 1 \\
\hline$x_{2}$ & 2,0 & 1,4 & 2,2 & 1,1 & 1,4 & 1,5 & 1,5 & 1,8 & 1,9 & 2,3 & 2,8 & 2,7 & 1,4 & 1,6 & 1,2 & 1,5 & 1,7 & 1,5 & 1,2 & 2,4 & 1,8 & 2,4 & 1 \\
\hline$x_{3}$ & 1,4 & 2,5 & 1,6 & 1,1 & 1,5 & 1,4 & 1,8 & 1,2 & 2,6 & 1,3 & 2,5 & 2,4 & 2,5 & 2,6 & 2,3 & 2,2 & 2,4 & 2,8 & 2,2 & 2,3 & 2,4 & 1,5 & 1 \\
\hline$x_{4}$ & 1,2 & 1,3 & 3,8 & 2,5 & 3,4 & 1,2 & 3,6 & 2,4 & 1,2 & 2,3 & 3,3 & 2,5 & 1,4 & 1,2 & 1,2 & 1,4 & 1,1 & 1,4 & 1,2 & 2,6 & 1,5 & 1,4 & 1 \\
\hline$x_{5}$ & 1,5 & 1,3 & 3,5 & 1,2 & 1,5 & 4,7 & 3,6 & 2,5 & 4,7 & 4,2 & 1,6 & 4,8 & 3,6 & 1,4 & 2,2 & 4,3 & 1,2 & 3,6 & 4,8 & 4,7 & 4,4 & 4,6 & 3 \\
\hline$x_{6}$ & 3,3 & 1,2 & 1,5 & 1,8 & 2,9 & 1,7 & 1,2 & 3,5 & 1,5 & 2,8 & 2,7 & 3,3 & 3,5 & 1,4 & 2,8 & 1,2 & 1,6 & 1,5 & 1,4 & 3,2 & 1,6 & 3,2 & 2 \\
\hline$x_{7}$ & 1,5 & 2,2 & 2,3 & 1,4 & 2,8 & 1,3 & 1,2 & 2,3 & 1,5 & 2,4 & 1,7 & 2,2 & 3,6 & 1,5 & 1,4 & 2,5 & 1,3 & 3,4 & 3,5 & 3,4 & 2,2 & 1,0 & 2 \\
\hline$x_{8}$ & 1,7 & 1,4 & 1,3 & 2,4 & 2,0 & 1,4 & 3,6 & 3,1 & 2,3 & 3,5 & 2,6 & 3,4 & 2,7 & 1,6 & 3,5 & 1,2 & 1,4 & 1,2 & 1,3 & 1,4 & 2,5 & 2,5 & 2 \\
\hline$x_{9}$ & 2,5 & 2,2 & 1,3 & 1,5 & 3,6 & 1,3 & 1,5 & 1,4 & 1,5 & 3,6 & 2,3 & 2,5 & 2,6 & 3,6 & 2,4 & 2,0 & 1,2 & 1,2 & 3,3 & 3,4 & 3,2 & 2,3 & 2 \\
\hline$x_{10}$ & 1,2 & 1,3 & 1,5 & 1,7 & 1,4 & 1,2 & 2,6 & 1,2 & 1,2 & 1,3 & 2,4 & 1,5 & 1,5 & 2,7 & 2,3 & 1,3 & 2,2 & 1,4 & 1,4 & 3,4 & 1,4 & 3,3 & 2 \\
\hline$x_{11}$ & 2,5 & 2,6 & 3,2 & 1,4 & 1,8 & 1,6 & 1,2 & 1,2 & 2,3 & 4,5 & 1,4 & 2,5 & 2,4 & 1,3 & 1,6 & 2,5 & 2,5 & 2,4 & 1,7 & 2,5 & 1,3 & 1,4 & 1 \\
\hline$x_{12}$ & 2,2 & 2,3 & 2,5 & 1,6 & 1,7 & 1,2 & 1,2 & 1,4 & 2,2 & 4,6 & 2,5 & 2,2 & 1,3 & 1,4 & 1,4 & 1,7 & 2,0 & 3,7 & 1,2 & 1,3 & 1,2 & 1,4 & 1 \\
\hline$x_{13}$ & 1,2 & 1,2 & 2,4 & 1,4 & 1,5 & 1,5 & 2,4 & 1,4 & 1,6 & 4,2 & 1,3 & 2,1 & 1,2 & 1,1 & 3,5 & 2,4 & 3,5 & 3,5 & 1,4 & 1,2 & 1,3 & 1,5 & 1 \\
\hline$x_{14}$ & 1,2 & 2,3 & 4,2 & 1,4 & 1,5 & 1,4 & 3,3 & 2,1 & 1,2 & 4,3 & 3,2 & 2,5 & 3,7 & 3,5 & 3,4 & 4,6 & 3,2 & 4,1 & 4,4 & 3,2 & 1,3 & 2,2 & 2 \\
\hline$x_{15}$ & 1,3 & 2,2 & 3,5 & 2,4 & 2,5 & 1,6 & 2,8 & 1,4 & 1,5 & 2,2 & 2,4 & 3,5 & 3,7 & 2,5 & 3,1 & 2,2 & 2,3 & 2,5 & 3,4 & 2,2 & 1,2 & 2,3 & 2 \\
\hline
\end{tabular}

Concrete data contents are shown in Tab. 3, where $x_{i}(i=1,2, \ldots, 15) \quad$ are selected samples, $a_{i}(i=1,2, \ldots, 22)$ are numerical value attributes, and $d$ is decision attribute.

Table 3 Neighborhood decision system [11] 
In the data processing of neighborhood rough sets, data will present differences in order of magnitudes and dimensions by the definition of rough set [11]. In order to obtain accurate data processing results, original data should be normalized before data processing of Eq. (14).

$$
f\left(x_{i}\right)=\frac{x_{i}-x_{\min }}{x_{\max }-x_{\min }}(i=1,2, \ldots, n)
$$

For definition 12 , the standard deviation of normalized attributes $a_{1}, a_{2}, \ldots, a_{22}$ is solved as below:

$$
\delta\left(a_{i}\right)=S t d a_{i} / \lambda
$$

$\lambda$ is a set parameter used to adjust neighborhood size according to data classification accuracy.

\subsection{Reduction Results}

Data in Tab. 3 are reduced to obtain 183 groups of reduction results. Different reduction sets are selected in projects under IPD pattern according to nature of participating enterprises and the definition of rough set, $a_{i}$ means the risk factors, $a_{5}$ (risk of laws and regulations), $a_{10}$ (contract risk), $a_{13}$ (communication risk between participants), $a_{15}$ (engineering change risk), $a_{20}$ (risk of insufficient experience of participants) and $a_{22}$ (change risk of market demands) are core elements of risks for construction projects under IPD pattern. $Y$ - axis means the weight of $a_{i}$ as is shown in Fig. 2.

Table 4 Weight table of risk factors [11]

\begin{tabular}{|c|c|c|c|c|c|c|c|c|c|c|c|}
\hline Risk & $a_{1}$ & $a_{2}$ & $a_{3}$ & $a_{4}$ & $a_{5}$ & $a_{6}$ & $a_{7}$ & $a_{8}$ & $a_{9}$ & $a_{10}$ & $a_{11}$ \\
\hline Weight & 0,018 & 0,031 & 0,051 & 0,016 & 0,112 & 0,005 & 0,044 & 0,028 & 0,032 & 0,063 & 0,016 \\
\hline Risk & $a_{12}$ & $a_{13}$ & $a_{14}$ & $a_{15}$ & $a_{16}$ & $a_{17}$ & $a_{18}$ & $a_{19}$ & $a_{20}$ & $a_{21}$ & $a_{22}$ \\
\hline Weight & 0,041 & 0,082 & 0,025 & 0,063 & 0,071 & 0,035 & 0,046 & 0,047 & 0,081 & 0,044 & 0,065 \\
\hline
\end{tabular}

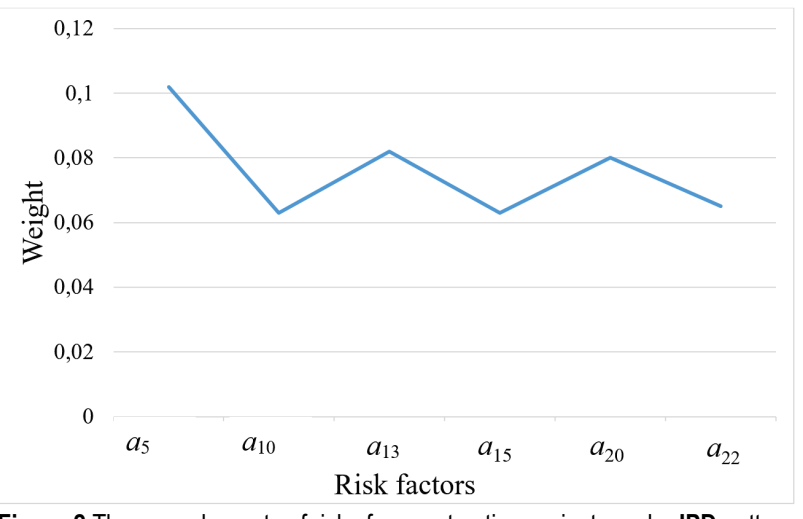

Figure 2 The core elements of risks for construction projects under IPD pattern [11]

The owner proposed new requirements when the steel structure of the health center was designed, hoping to change the back-to-back ward into the same direction. At the end of the design phase, when the owner proposes a design change temporarily, considering that the main subcontractor may have purchased equipment and allocated labor, the design unit will undergo a series of processes such as feasibility analysis after the modification is made. It is difficult for traditional management methods to quickly change ideas and make new adjustments. With the inherent flexibility of the IPD team, the design process of the design unit and the construction unit is a unified process, and the main contractor knows the progress of the project. For the latest ideas proposed by the owner, after the entire IPD team believes that it is feasible, the solution can be adjusted in a timely manner without increasing cost or time, so that the hospital's facilities can better meet customer requirements.

\section{CONCLUSION}

Risk factor sets, which possibly appeared in IPD projects, were evaluated and calculated through the attribute reduction algorithm based on the rough set theory. Core elements of risk factor sets were obtained as risk of laws and regulations, contract risk. Communication risk among participants, engineering change risk, risk of insufficient experience of participants and change risk of market demands, weights of risk factors were calculated through attribute frequency as shown in Tab. 3 and Tab. 2, and the reasonability of attribute reduction results was verified. The contributions of this article are as follows. Based on the improved neighborhood rough set theory, the risk factors of complex projects under the BIM-based IPD model are reduced and selected, and the most important risk factors for the successful completion of complex projects under the BIM-based IPD model are obtained. No discretization is required for continuous data, the original data attributes can be maintained, and the accuracy of rough set theory analysis can be improved. As there are relatively few laws and regulations and models of contract related to IPD pattern at present, risk of laws and regulations and contract risk have become the main problems faced in the complete and smooth implementation of IPD projects.

\section{REFERENCES}

[1] AIA National/AIA California Council. Integrated Project Delivery: A Guide [EB/OL]. [2016-5-12]. https://en. Wikipedia.org/wiki/Integrated project delivery.

[2] Vega, A. O. (2009). Risk Allocation in Infrastructure Financing. Journal of Structured Finance, 3(2), 38-42. https://doi.org/10.3905/jsf.3.2.38

[3] Ahwirengobeng, F. \& Mokgohlwa, J. P. (2002). Entrepreneurial risk allocation in public-private infrastructure provision in South Africa. South African Journal of Business Management. https://doi.org/10.4102/sajbm.v33i4.709

[4] Govan, P. B. \& Damnjanovic, I. (2016). The ResourceBased View on Project Risk Management. Journal of Construction Engineering \& Management, 142(9). https://doi.org/10.1061/(ASCE)C0.1943-7862.0001136

[5] Elbarkouky, M. M. G., et al. (2016). Fuzzy Arithmetic Risk Analysis Approach to Determine Construction Project Contingency. Journal of Construction Engineering \& Management, 142(12), 04016070. https://doi.org/10.1061/(ASCE)C0.1943-7862.0001191 
[6] Nasirzadeh, F. \& Mazandaranizaded, H. (2016). Quantitative Risk Allocation in Construction Project U sing CooperativeBargaining Game Theory. International Journal of Civil Engineering, 14(3), 161-170.

https://doi.org/10.1007/s40999-016-0011-8

[7] Karkas, K. \& Dikmen, I. (2013). Multiagent System to Simulate Risk-Allocation and Cost-Sharing Processes in Construction Projects. Journal of Computing in Civil Engineering, 27 (3), 307-319. https://doi.org/10.1061/(ASCE)CP.1943-5487.0000218

[8] Francesca, M. (2007). A Game Theory Approach for the Allocation of Risks in Transport Public Private Partnerships. International Journal of Project Management, 25(3), 213218. https://doi.org/10.1016/j.jproman.2006.06.003

[9] Dalkey, N. \& Helmer, O. (1963). An experimental application of the Delphi method to the use of experts. Management science, 9(3), 455-468. https://doi.org/10.1287/mnsc.9.3.458

[10] Pawlak, Z. (1982). Rough Set. International Journal of Computer and Information Science, (11), 341-356. https://doi.org/10.1007/BF01001956

[11]Dossick, C. S., Azari, R., Kim, Y.-W., \& El-Anwar, O. (2013). IPD in Practice: Sustaining Collaboration in Healthcare Design and Construction. AEI, (12), 34-38. https://doi.org/10.1061/9780784412909.036

\section{Contact information:}

\section{Weibing CHEN}

School of Civil Engineering and Architecture,

Wuhan University of Technology,

Wuhan 430070, China

\section{Junwu WANG}

(Corresponding author)

School of Civil Engineering and Architecture,

Wuhan University of Technology,

Wuhan 430070, China

Email:wangjunwu_whut@163.com

\section{Chengfu WANG}

Chongqing University of Technology,

Chongqing 400054, China 